into. In the Bantu language Kivunjo, he tells us, the verb form Näikìmlyïà, meaning "He is eating it for her", is one of about half a million possible forms, which native speakers have no trouble in assembling on the fly from bits and pieces such as these:

$\mathrm{N}$ - A marker indicating that the word is the 'focus' of that point in the conversation.

-ä- A subject agreement marker, identifying the eater as falling into class 1 of the 16 gender classes, 'human singular'. Other genders (kinds, not sexes) embrace nouns that pertain to several humans, thin or extended objects, objects that come in pairs or clusters, the pairs or clusters themselves, instruments, animals, body parts, diminutives (small or cute versions of things), abstract qualities, precise locations and general localities.

-i- Present tense. Other tenses in Bantu can refer to today, earlier today, yesterday, no earlier than yesterday, yesterday or earlier, in the remote past, habitually, ongoing, consecutively, in the future, at an indeterminate time, not yet and sometimes.

-kì- An object agreement marker, in this case indicating that the thing eaten falls into gender class 7

And so on.

One of the mysteries Pinker does not resolve for the inquisitive reader is the precise relationship between the earlyand the late-flowering varieties of Chomskian linguistic theory. His reasons may be diplomatic, or simply expository: a fear of the pedagogic confusion that might result from attempting to superimpose the most recent version of "GB theory" on the "Xbar theory" to which he has so carefully introduced the reader. Perhaps he merely felt it wiser to hide the antics of the professional linguists from the searching gaze of student innocence.

For all other readers, The Language Instinct will illuminate every facet of human language: its biological origin, its uniqueness to humanity, its acquisition by children, its grammatical structure, the production and perception of speech, the pathology of language disorders and the unstoppable evolution of languages and dialects. With its wealth of examples, its flawless typesetting, its wide-ranging bibliography and its irresistible good humour, Pinker's book is certain to increase its readers' respect for the amazing natural phenomenon that the author and his colleagues have made their life's (to a maven, lives'?) study.

Christopher Longuet-Higgins is in the Laboratory of Experimental Psychology, University of Sussex, Falmer, Brighton BN1 9QG, UK.

\title{
Reactions speak louder than words
}

\section{Roald Hoffmann}

La Parole des Choses. By Pierre Laszlo. Hermann: 1993. Pp. 320. FFr160.

THERE has always been a link between language and chemistry. Lavoisier begins his revolutionary Traité Elémentaire de Chimie with a quote from the Abbe de Condillac: "We think only through the medium of words. Languages are true analytical methods." Lavoisier then reflects on his own work: "Thus, while I thought of myself employed only in forming a Nomenclature... my work transformed itself by degrees, without my being able to prevent it, into a treatise upon the Elements of Chemistry". The distinguished European writer Elias Canetti, author of a remarkable study of mass behaviour, Crowds and Power, and a striking novel of the 1930s, Auto da Fé, earned a PhD in chemistry. He credits chemistry with teaching him the importance of linguistic structure. And Benjamin Lee Whorf, the great American linguist who made a case for language shaping culture, trained as a chemical engineer at the Massachusetts Institute of Technology. Whorf was not averse to "an occasional chemical simile". In an essay on languages and logic he writes: "the way the constituents are put together in these sentences of Shawnee and Nootka suggests a chemical compound, whereas their combination in English is more like a mechanical mixture".

Pierre Laszlo's rich and original book explains the link between language and chemistry. Laszlo makes an analogy between molecules and their transformations on one hand and linguistic structures such as morphemes, phonemes, ideograms and pictograms, transformations of mode and description on the other. If the latter sound abstruse to a chemist, imagine what sense a functional group, elementary reactions, $\mathrm{C}_{6} \mathrm{H}_{6}$ or a benzene ring drawn out (of course, without a $\mathrm{C}$ or $\mathrm{H}$ indicated) would make to a linguist other than the late Whorf.

La Parole des Choses (perhaps one way to translate the title is "The Way Things Speak", but that doesn't capture the allusion to the structuralist and literary theory use of parole) is actually two books. The working out of the language-chemistry analogy is one theme that runs through this readable volume. Another theme, interwoven, is simply that of the beauty of chemistry. The logic of the molecular science is masterfully explicated, with few compromises, for an intelligent reader outside chemistry. For instance, the book contains a beautiful discussion of nitrogen inversion, the best short introduction to nuclear magnetic resonance I've read and even a brief account of femtosecond reactions. But consistent with Laszlo's broad cultural theme, these expositions are juxtaposed with, respectively, a quote from Gérard de Nerval (a nineteenth-century French poet and writer), a touching retelling of some of Laszlo's misadventures in taking his first NMR spectrum in 1961, and an excerpt from Blake's Milton.

Insights and information abound. The linguistic analogy builds convincingly, but one does not have to buy into it to appreciate the capsule description of the economics of the perfume industry (and the composition of "Obsession") or the surprising use by Hegel of Berzelius's electrochemical theory or the prolonged alchemical and chemical use of the word menstruum for solvent.

Let me see if I can put my finger more precisely on the value in this book. To deconstruct scientific texts is so easy, too easy. Ditto for the use of literary allusions to pretty up science writing. Laszlo does something more - he sets up an intriguing analogy, of the processes of language and chemistry, and lets the analogy illuminate each field.

Roald Hoffmann is in the Department of Chemistry, Cornell University, Ithaca, New York 14853-1301, USA.

\section{Linguistic geography}

\section{Mark Pagel}

Atlas of the World's Languages. Edited by Christopher Moseley and R. E. Asher. Routledge: 1994. Pp. 372. £395, $\$ 599.95$.

FIFTEEN years ago, one respected encyclopaedia of the world's languages placed the number of known extant human languages at around 4,550. By 1984 a new survey found that at least 5,450 different languages were being spoken on Earth. The number rose to 6,170 by the time of the appearance of the eleventh edition of Ethnologue: Languages of the World (edited by B. F. Grimes, Summer Institute of Linguistics, 1988), and to more than 6,500 by the twelfth edition. The true number is probably even higher. This diversity of languages, all of them spoken by the same species, is testimony to the human - one might say - compulsion to speak. Unlike chimpanzees, which need daily operant prodding to use even a small repertoire of words, it is difficult to stop humans from using language: linguists 